\title{
Online Handwritten Text Recognition for Indian Scripts
}

\author{
Ravneet Kaur ${ }^{1}$, Dharam Veer Sharma ${ }^{2}$ \\ ${ }^{I}$ Department of Computer Science, Guru Nanak National College, Doraha, India. \\ ${ }^{2}$ Department of Computer Science, Punjabi University, Patiala, India. \\ ${ }^{1}$ mail2ravneetkaur@gmail.com ${ }^{2}$ dveer72@hotmail.com
}

\begin{abstract}
Online Handwriting Recognition has been a rigorous research area for the last few decades. Substantial amount of work has been reported on the online handwriting recognition of Western. Chinese, Japanese, Korean and Arabic Scripts, but few related to Indian scripts. In this paper a review of online HCR work on almost all popular Indian scripts such as Devanagari, Gurmukhi, Bangla, Tamil, Telugu, Malayalam, Urdu, Kannada, Oriya, and Gujarati is presented. The review is organized into 7 sections. Section 1 covers introduction. Properties of Indian scripts and general architecture of online HCR is given in section 2 and 3. In section 4, research work done on online handwriting for Indian scripts is summarized. Challenges of online HCR are discussed in section 5. The scope of future work and further steps needed for Indian script based online HCR development are discussed in section 6. Conclusions are given in section 7.
\end{abstract}

Keywords: Online Handwritten text Recognition, Indian Scripts, Character Recognition, OCR, HCR.

Date of Submission: 03-07-2017

Date of acceptance: 17-07-2017

\section{Introduction}

With the development of technology and portable computing devices such as PDAs and handheld computers, Non-Keyboard methods are providing an efficient and natural way for man machine interface. Most promising options are voice based and pen based inputs. Online handwriting refers to writing through a special pen on an electronic surface and recognition of online handwriting is the tracking of hand movements, the way user writes. Practical applications of online handwriting recognition are: (i) Pen based form filling, (ii) Word processing, (iii) Natural language processing, and (iv)Usage of online handwriting recognition in conjunction with speech synthesis, to empower people with vocal disability to communicate with others [46]. Various Designers have been actively involved in developing online Handwritten character recognition systems for Indian scripts (N Joshi et al.[6,27]; A Sharma et al. [11,51], R.K Sharma et al.[11,14,15,16], Sachan and Lehal et al.[12,13] ,U. Bhattacharya et al.[17,19,20], A G. Ramkrishnan etal.[6,27,30,31,32,33,34,43,44,46], R. Kunwar et al.[30,31,44]). Little work has also been reported for bilingual Online HCR(S Lakshami et al.[7, 35], A.Arora and Namboodiri et al.[38]) and HCR for Mobile Devices (A Sharma et al.[52]). In this paper an overview of online handwritten character recognition for Indian scripts is reported. Most of the articles are published from the year 2004 onwards. The comparison of all reported methods is presented in tabular form and is done with respect to pre processing, feature set, classifier, post processing, and reported accuracy.

\section{Properties Of Scripts}

India is a Multi-Lingual, Multi-Script country. Devnagari, Gurmukhi, Bangla, Tamil, Telgu, Urdu, Oriya, Gujarati, Kannada and Malayalam are 10 official Indian scripts. Most of these scripts are originated from an ancient script called Brahmi. Examples of these scripts are shown in figure1. These Indian scripts differ by variety of visual characteristics; and also share some important similarities.

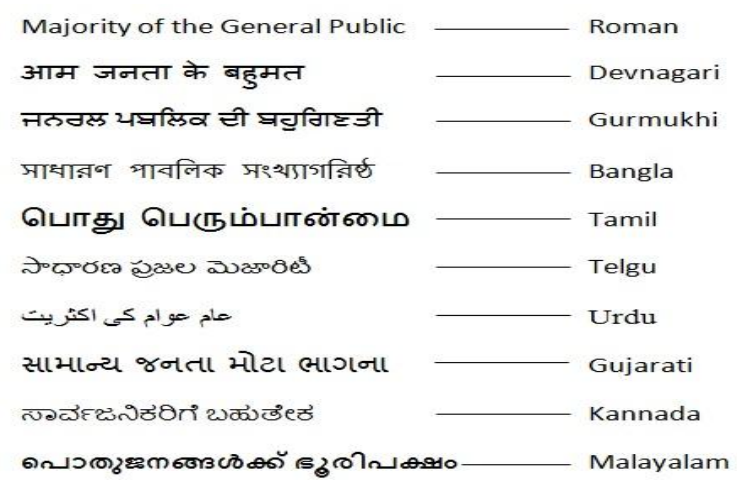

Figure 1 : Examples of Indian Scripts. 
A brief overview of General Structural properties of these scripts is discussed below:

- Character set of most scripts is divided into two categories: Basic and Compound Characters. (i) Basic Character is collection of vowels and consonants. Devnagari has 11 vowels and 33 simple consonants, Gurmukhi has 9 vowels and 41 consonants, Bangla has 11 vowels and 39 consonants, Tamil has 12 vowels and 23 consonants, Telgu has 14 vowels and 34 consonants, Kannada has 14 vowels and 34 consonants, Gujarati has 11 vowels and 34 consonants, Malayalam has 18 vowels, 36 consonants, and 5 half consonants, Oriya has 12 vowels and 35 consonants; (ii) In most Indian scripts (except Tamil and Gurmukhi) there are compound character, which are formed by combining two or more basic character. The shape of combined characters is usually more complex than basic character [1].

- There is no concept of upper and lower case in Indian scripts.

- Writing style of Devnagari, Gurmukhi, Kannada, Tamil and Telgu, Malayalam, Bangla, Guajarati is from Left to Right whereas, Urdu is written from Right to Left.

- In some Indian scripts (like Devnagari, Bangla, Gurmukhi etc.) many characters have a horizontal line at the upper part called headline.

- In most Indian scripts the text is partitioned into three zones- the upper zone, Middle zone and lower zone.

\section{Steps In Online HCR Systems}

Online HCR system converts user handwritten information into text. The recognition of online handwritten characters includes following phases: data acquisition, pre processing, feature extraction, classification, recognition and post-processing. The output obtained from one phase becomes input for the next phase. These phases are illustrated in figure 2 .

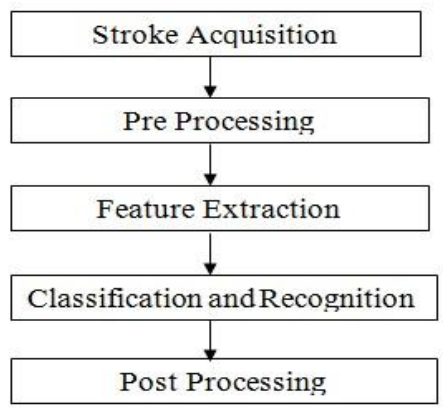

Figure 2: General steps in Online Handwritten Text Recognition System

Writing on mobile phone, tablet, PDA or any online input device, generate a sequence of strokes. These Strokes are pre processed to extract useful features. Pre processed strokes are then sent to recognition engine which then accept or reject the stroke based on pre defined rules. Each script has its own writing rules depending upon the properties of the script. Steps involved in online Script recognition are:

I. Data Acquisition: Data is collected during the input. Parameters related to pen tip like position, acceleration, velocity and sometimes pressure on the writing surface are used for data acquisition.

II. Pre processing: In this step, noise and other undesirable effects are reduced to improve the data for the recognition process. Typically, Normalization, Smoothing, Resampling, Dehooking, Thinning, Noise Reduction is applied.

III. Feature Extraction: The relevant information from the input is extracted for further processing. The challenge in this phase is to extract a minimal set of features with maximum data recognition. Typically Shape, Directional, Length, Angle features are extracted. High recognition performance could be achieved by selecting suitable set of features.

IV. Classification and Recognition: Methods such as SVM, MQDF, DWT, HMM, Neural Networks are often used for handwriting recognition. The goal is to find the optimal letter for a given handwritten input. The letter corresponding to the maximum probability is reported as the recognized letter.

V. Post processing: Post processing is performed in order to improve the performance of the system. It includes the procedure of correcting misclassified results by applying linguistic knowledge [7].

\subsection{Recognition of Devanagari Script}

\section{Online HCR Systems For Indian Scripts}

Devanagari is the most widely used Indian writing system. The first system on online recognition of devanagari script was introduced by Connel et al. [5]. They have used combination of Hidden Microwave Model and Nearest Neighbor Classifier for classification and capturing different levels of offline and online features yielding a classification accuracy of $86.5 \%$. 
Table 1. Existing Devnagari Online Handwritten Character Recognition System

\begin{tabular}{|c|c|c|c|c|c|c|c|c|}
\hline Author & Input & Pre-processing & Features & Method & $\begin{array}{l}\text { Post__ } \\
\text { Processing }\end{array}$ & $\begin{array}{l}\text { Training } \\
\text { Set }\end{array}$ & Test Set & $\begin{array}{l}\text { Recognition } \\
\text { Rate }\end{array}$ \\
\hline $\begin{array}{l}\text { Scott D } \\
\text { Connell } \\
\text { et al.[5] } \\
(2000)\end{array}$ & $\begin{array}{l}\text { Online } \\
\text { Handwritten } \\
\text { Character }\end{array}$ & \begin{tabular}{l|} 
Size \\
Normalization, \\
Quantization
\end{tabular} & $\begin{array}{l}\text { Local Online Features, } \\
\text { Global Offline Features }\end{array}$ & $\begin{array}{l}\text { HMM and } \\
\text { Nearest } \\
\text { neighbour } \\
\text { Classifier }\end{array}$ & - & - & $\begin{array}{l}1600 \\
\text { characters }\end{array}$ & $86.5 \%$ \\
\hline $\begin{array}{l}\text { Niranjan } \\
\text { Joshi } \\
\text { et al.[6] } \\
(2005)\end{array}$ & $\begin{array}{l}\text { Online } \\
\text { Handwritten } \\
\text { Character }\end{array}$ & $\begin{array}{l}\text { Resampling and } \\
\text { low pass } \\
\text { Filtering }\end{array}$ & $\begin{array}{l}\text { Stroke level features such } \\
\text { as mean }(\mathrm{x}, \mathrm{y}) \text { value, } \\
\text { Length, Offline features, } \\
\text { Positional cues and } \\
\text { Directional codes }\end{array}$ & $\begin{array}{l}\text { Structural } \\
\text { Recognition, } \\
\text { Feature based } \\
\text { Recognition and } \\
\text { Output Mapping }\end{array}$ & - & $\begin{array}{l}1487 \\
\text { characters }\end{array}$ & $\begin{array}{l}441 \\
\text { characters }\end{array}$ & $94.49 \%$ \\
\hline $\begin{array}{l}\text { Bhushan C } \\
\text { Bhokse, } \\
\text { Bhushan S. } \\
\text { Thakare } \\
\text { et al.[6] } \\
(2012)\end{array}$ & $\begin{array}{l}\text { Online } \\
\text { Handwritten } \\
\text { Character }\end{array}$ & $\begin{array}{l}\text { Stroke Joining, } \\
\text { Scaling and } \\
\text { Shifting, } \\
\text { Down sampling } \\
\text { and } \\
\text { Quantization }\end{array}$ & $\begin{array}{l}\text { Character Pattem, } \\
\text { Length, Directional Code, } \\
\text { Vertical Line and Half } \\
\text { Vertical Line, Horizontal } \\
\text { Line and Half Horizontal } \\
\text { Line }\end{array}$ & $\begin{array}{l}\text { Dynamic Time } \\
\text { Wrapping } \\
\text { Algorithm }\end{array}$ & - & - & - & $64 \%$ \\
\hline $\begin{array}{l}\text { Sharuti } \\
\text { Kabatur } \\
\text { et al.[10] } \\
(2012)\end{array}$ & $\begin{array}{l}\text { Online } \\
\text { Handwritten } \\
\text { Character }\end{array}$ & $\begin{array}{l}\text { Smoothing and } \\
\text { De-noising, } \\
\text { Normalization }\end{array}$ & $\begin{array}{l}\text { Speed of Writing, angular } \\
\text { Velocity and order of } \\
\text { Strokes. }\end{array}$ & Neural Network & - & $\begin{array}{l}2760 \\
\text { Samples }\end{array}$ & $\begin{array}{l}2760 \\
\text { samples }\end{array}$ & $\begin{array}{l}96.268 \% \text { (with } 2 \\
\text { neural Network) } \\
97.283 \% \text { (with } 2 \\
\text { neural network) }\end{array}$ \\
\hline
\end{tabular}

Joshi et al. [6] have developed a system for automatic recognition of isolated handwritten devanagari character obtained by linearizing consonant conjuncts. Resampling and low pass filtering are used as preprocessing techniques. The recognition methodology used is broadly divided into three modules: Structural Recognition, Feature Based Recognition, and Output Mapping. In sequential data testing, the system recognition accuracy of $94.49 \%$ is reported.

System for Online Handwritten Character Recognition of Devanagari and Telugu Characters has been proposed by Swethalakshmi et al. [35] where, Support vector machines are used for constructing the stroke recognition engine. Also a study has been done by Swethalakshmi et al. [7], stroke based HCR systems, which use SVMs for stroke classification and a rule based approach for character identification, are proposed for two major Indian writing systems, Devanagari and Tamil. Pre processing steps: Normalization, Smoothing, and Interpolation are performed to remove variations and noise and a uniform representation of input strokes is obtained. Spatiotemporal, Spectral, and Spatiostructural features are used for obtaining three different representations of stroke, and classification accuracy of $95.13 \%$ for spatiotemporal, $95.29 \%$ for spectral, and $90.86 \%$ for spatiostructural features is reported for devnagari script. Post processing steps: Disambiguation and Regrouping are performed to resolve the ambiguities among confusable strokes and to identify non-proximal units. Bhokse et al. [8] have presented a recognition system using DTW technique. The down sampled and quantized input character pattern are preprocessed to extract structural features. An adequate accuracy of $64 \%$ is reported. Deepika et al. [9] have developed an online handwritten Devanagari Numeral recognition system using SVM. The recognition task is divided into 4 phases namely: Data collection, Pre processing, Feature Extraction, and Recognition. Recognition is done using four kernel functions (linear, polynomial, RBF, sigmoid) of SVM by dividing the data into six schemes depending on the features extracted. Results obtained are reasonably good when the linear kernel is used as compared to the other kernels. The highest accuracy reported by the linear kernel is $98.90 \%$. Sharuti et al. [10] have proposed a Neural Network based system for recognition of online handwritten devanagari characters, where the mode of character input is through computer mouse. The recognition rate of $97.2 \%$ is achieved after testing of algorithm on 2760 characters. Table 1 gives an overview of the online handwritten recognition systems for devanagari characters and numerals.

\subsection{Recognition of Gurumukhi Script}

Gurumukhi script is $14^{\text {th }}$ most widely used script in the world. Sharma et al. [11] introduced a writer independent system for online Gurumukhi script recognition. New recognition method, Small Line Segment was introduced based on chain code rule and elastic matching technique. Recognition rate of $94.59 \%$ is reported using small line segments method. Post processing phase is also discussed which includes verification of recognized strokes through features of character in the script. 
Table 2. Existing Gurmukhi Online Handwritten Character Recognition System

\begin{tabular}{|c|c|c|c|c|c|c|c|c|}
\hline Author & Input & Pre-processing & Features & Method & $\begin{array}{l}\text { Post_- } \\
\text { Processing }\end{array}$ & $\begin{array}{l}\text { Training } \\
\text { Set }\end{array}$ & Test Set & $\begin{array}{l}\text { Recognition } \\
\text { Rate }\end{array}$ \\
\hline $\begin{array}{l}\text { Anuj } \\
\text { Sharma } \\
\text { et al.[11] } \\
(2009)\end{array}$ & $\begin{array}{l}\text { Online } \\
\text { Handwritten } \\
\text { Characters }\end{array}$ & $\begin{array}{l}\text { Size normalization and } \\
\text { centring of strokes, } \\
\text { Smoothing of stroke, } \\
\text { Slant correction of stroke } \\
\text { \& resampling of points in } \\
\text { stroke, Interpolating } \\
\text { missing points in stroke. }\end{array}$ & $\begin{array}{l}\text { High Level Features- } \\
\text { Loop, crossing; dots, } \\
\text { straight line and } \\
\text { headline. } \\
\text { Low Level Features- } \\
\text { Position of stroke } \\
\text { area, length, } \\
\text { curliness,slope }\end{array}$ & $\begin{array}{l}\text { Small } \\
\text { Line Segment } \\
\text { Method } \\
\text { Based on Elastic } \\
\text { Matching and } \\
\text { chain code } \\
\text { Technique }\end{array}$ & $\begin{array}{l}\text { Verification } \\
\text { of } \\
\text { recognized } \\
\text { strokes } \\
\text { through } \\
\text { features of } \\
\text { characters in } \\
\text { script }\end{array}$ & - & $\begin{array}{l}2460 \\
\text { characters } \\
\text { from } 60 \\
\text { users }\end{array}$ & $\begin{array}{l}94.59 \% \\
\text { Using Small } \\
\text { Line } \\
\text { Segmentatio } \\
\mathrm{n}\end{array}$ \\
\hline $\begin{array}{l}\text { Manoj K } \\
\text { Sachan } \\
\text { et al. } \\
{[12,13]} \\
(2011)\end{array}$ & $\begin{array}{l}\text { Online } \\
\text { Handwritten } \\
\text { Words }\end{array}$ & $\begin{array}{l}\text { Rescaling, } \\
\text { Duplicate Point Removal }\end{array}$ & $\begin{array}{l}\text { Distributed } \\
\text { Directional Features }\end{array}$ & $\begin{array}{l}\text { (a) Extraction of } \\
\text { strokes based on } \\
\text { position, } \\
\text { pressure, button } \\
\& \text { time } \\
\text { (b) Merging of } \\
\text { Sub strokes }\end{array}$ & - & - & $\begin{array}{l}2150 \\
\text { words } \\
\text { from } 50 \\
\text { users }\end{array}$ & $76 \%$ \\
\hline $\begin{array}{l}\text { Shivali et } \\
\text { al.[14] } \\
(2011)\end{array}$ & $\begin{array}{l}\text { Online } \\
\text { Handwritten } \\
\text { Numerals }\end{array}$ & $\begin{array}{l}\text { Size normalization and } \\
\text { centring, interpolating } \\
\text { missing points, } \\
\text { resampling, smoothing }\end{array}$ & $\begin{array}{l}\text { Points Generated } \\
\text { after pre-processing } \\
\text { phase is used as } \\
\text { feature for } \\
\text { recognition } \\
\end{array}$ & $\begin{array}{l}\text { Support Vector } \\
\text { Machine }\end{array}$ & - & $\begin{array}{l}80 \% \text { of } \\
\text { Data }\end{array}$ & $\begin{array}{l}20 \% \text { of } \\
\text { Data }\end{array}$ & $\begin{array}{l}97.5 \% \text { (with } \\
40 \text { resampled } \\
\text { points Using } \\
\text { linear kemel) }\end{array}$ \\
\hline $\begin{array}{l}\text { R. } \\
\text { Aggarwal } \\
\text { et al.[15] } \\
(2012)\end{array}$ & $\begin{array}{l}\text { Online } \\
\text { Handwritten } \\
\text { Strokes }\end{array}$ & $\begin{array}{l}\text { Size Normalization and } \\
\text { Centring, Interpolating } \\
\text { Missing Points, } \\
\text { Smoothing, Resampling }\end{array}$ & $\begin{array}{l}\text { Points Generated } \\
\text { after pre processing } \\
\text { phase is used as } \\
\text { feature for } \\
\text { recognition }\end{array}$ & $\begin{array}{l}\text { Support Vector } \\
\text { Machine }\end{array}$ & - & - & $\begin{array}{l}300 \text { words } \\
\text { from } 3 \\
\text { users }\end{array}$ & $\begin{array}{l}98.45 \% \\
\text { (withoutpre } \\
\text { processing) } \\
98.92 \% \text { (with } \\
\text { preprocessed } \\
\text { strokes) }\end{array}$ \\
\hline $\begin{array}{l}\text { Dushyant } \\
\text { Khurana } \\
\text { et al.[16] } \\
(2013)\end{array}$ & $\begin{array}{l}\text { Online } \\
\text { Handwritten } \\
\text { Characters }\end{array}$ & $\begin{array}{l}\text { Removal of duplicate } \\
\text { points, Size } \\
\text { Normalization \& } \\
\text { Centring, Missing point } \\
\text { Interpolation, Resampling }\end{array}$ & $\begin{array}{l}\text { Points Generated } \\
\text { after pre processing } \\
\text { phase is used as } \\
\text { feature for } \\
\text { recognition }\end{array}$ & $\begin{array}{l}\text { Support Vector } \\
\text { Machine }\end{array}$ & $\begin{array}{l}\text { Database of } \\
\text { Rules for } \\
\text { Creating a } \\
\text { Character is } \\
\text { used. }\end{array}$ & $\begin{array}{l}75 \% \text { of } \\
\text { Data }\end{array}$ & $\begin{array}{c}25 \% \text { of } \\
\text { Data }\end{array}$ & $94.4 \%$ \\
\hline
\end{tabular}

Sachan et al. $[12,13]$ proposed a system for online Gurumukhi script recognition. Pre-processing steps rescaling and duplicate point removal are performed on input data. The segmentation algorithm consist of two phases namely extraction of strokes and merging of strokes. Segmented shapes are processed to extract Distributed directional features. Feature data is fed to the recognition engine which is nearest neighbour classifier. Average accuracy of $76 \%$ is achieved by the system.

Shivali et al. [14] has reported work for recognition of Online Handwritten Punjabi Numerals using Support Vector Machine. Recognition accuracy of $97.5 \%$ is achieved with 40 resampled points using linear kernel. Work for recognition of Online Handwritten Gurmukhi Strokes using SVM has been done by Aggarwal et al. [15]. An overall accuracy of $98.45 \%$ without applying pre-processing and $98.92 \%$ with pre-processing phase has been reported. Khurana et al. [16] has also reported work for online Gurumukhi text recognition by using SVM with accuracy rate of $94.4 \%$. Table2 gives an overview of the online handwritten recognition systems for Gurumukhi characters and numerals.

\subsection{Recognition of Bangla Script}

Bangla script is used by more than 200 million people of India and Bangladesh. Online Bangla cursive words recognition system was proposed by Bhattacharia et al. [17]. An analytic recognition approach is proposed. 8-directional feature vector along with the Modified Quadratic Discriminant Function is used for recognition of segmented strokes. Overall word level recognition accuracy $82.34 \%$ is reported. System for online recognition of handwritten Bangla character is presented by Bandopadhyay et al. [18]. A DTW based classifier is used to identify strokes. Overall recognition accuracy of $97.33 \%$ is reported for writer dependent system. Parui et al. [19] presented a system where, Recognition of the strokes forming the shape of an unknown character sample is done by the HMM classifier. The classification rate reported by the proposed scheme is $87.7 \%$ whereas classification accuracy at the stroke level is $84.6 \%$. 
Table 3. Existing Bangla Online Handwritten Character Recognition System

\begin{tabular}{|c|c|c|c|c|c|c|c|c|}
\hline Author & Input & Pre-processing & Features & Method & $\begin{array}{l}\text { Post_ } \\
\text { Processing }\end{array}$ & $\begin{array}{l}\text { Training } \\
\text { Set }\end{array}$ & TestSet & $\begin{array}{l}\text { Recognition } \\
\text { Rate }\end{array}$ \\
\hline $\begin{array}{l}\text { U } \\
\text { Bhattach } \\
\text { arya } \\
\text { et al.[17] } \\
(2008)\end{array}$ & $\begin{array}{l}\text { Online } \\
\text { Handwritten } \\
\text { Words }\end{array}$ & $\begin{array}{l}\text { Noise Removal } \\
\text {,Shift of Origin } \\
\text {,Smoothing } \\
\text { and Resampling } \\
\text { of points }\end{array}$ & $\begin{array}{l}\text { Width and height of stroke, } \\
\text { angle, directional features, } \\
\text { coordinates of the center of } \\
\text { gravity }\end{array}$ & $\begin{array}{l}8 \text { directional feature } \\
\text { vector along with the } \\
\text { Modified quadratic } \\
\text { discriminant function } \\
\text { MQDF) classifier. }\end{array}$ & - & - & - & $82.34 \%$ \\
\hline $\begin{array}{l}\text { Asok } \\
\text { Bandopa } \\
\text { dhyay } \\
\text { et al.[18] } \\
(2008) \\
\end{array}$ & $\begin{array}{l}\text { Online } \\
\text { Handwritten } \\
\text { Characters }\end{array}$ & $\begin{array}{l}\text { Resampling, } \\
\text { Smoothing and } \\
\text { Normalization } \\
\text { of Strokes }\end{array}$ & $\begin{array}{l}\text { Directional Features, } \\
\text { Shape Based Features }\end{array}$ & DWT Classifier & - & - & - & $97.33 \%$ \\
\hline $\begin{array}{l}\text { SK } \\
\text { Pauri } \\
\text { et al.[19] } \\
(2008)\end{array}$ & $\begin{array}{l}\text { Online } \\
\text { Handwritten } \\
\text { Characters }\end{array}$ & $\begin{array}{l}\text { Snoothing, } \\
\text { Nomalization }\end{array}$ & $\begin{array}{l}\text { Shape and size of sub } \\
\text { stroke, Points forming the } \\
\text { strokes, distance between } \\
\text { points, angle, Direction, } \\
\text { Length, Height of Stroke. }\end{array}$ & HMM & - & - & - & $\begin{array}{l}87.7 \% \text { (Class } \\
\text { ficationrate) }\end{array}$ \\
\hline $\begin{array}{l}\text { Gemot } \\
\text { A.F } \\
\text { et al.[20] } \\
(2010)\end{array}$ & $\begin{array}{l}\text { Online } \\
\text { Handwritten } \\
\text { Words }\end{array}$ & $\begin{array}{l}\text { Size } \\
\text { Nomalization, } \\
\text { Smoothing and } \\
\text { Resampling }\end{array}$ & $\begin{array}{l}\text { For each sub-stroke } 8 \\
\text { scalar feature value } \\
\text { representingits shape, size } \\
\text { and relative position are } \\
\text { computed }\end{array}$ & $\begin{array}{l}\text {-System was } \\
\text { developed using open } \\
\text { source environment } \\
\text { ESMERALDA } \\
\text {-Semi-continuous } \\
\text { HMMs }\end{array}$ & - & - & - & $\begin{array}{l}93.1 \% \text { (Conte } \\
\mathrm{xt} \\
\text { Dependent) }\end{array}$ \\
\hline $\begin{array}{l}\text { Chandan } \\
\text { Biwas } \\
\text { et al.[21] } \\
(2012)\end{array}$ & $\begin{array}{l}\text { Online } \\
\text { Handwritten } \\
\text { Characters }\end{array}$ & $\begin{array}{l}\text { Nomalization, } \\
\text { Remove Local } \\
\text { Noise, } \\
\text { Resampling, } \\
\text { Smoothing }\end{array}$ & $\begin{array}{l}8 \text { stroke features } \\
\text { (Computed on the basis of } \\
\text { angle, centre of gravity } \\
\text { and length of stroke) }\end{array}$ & $\begin{array}{l}\text {-HMM Classifier } \\
\text {-Dirichlet Distributer } \\
\text { for stroke classes }\end{array}$ & - & $\begin{array}{l}29951 \\
\text { character } \\
\text { samples }\end{array}$ & $\begin{array}{l}8616 \\
\text { Samples }\end{array}$ & $91.85 \%$ \\
\hline $\begin{array}{l}\text { KRoy et } \\
\text { al.[22] } \\
(2012)\end{array}$ & $\begin{array}{l}\text { Online } \\
\text { Handwritten } \\
\text { Characters }\end{array}$ & Smoothing & $\begin{array}{l}\text { Structural Features, } \\
\text { Point based futures }\end{array}$ & $\begin{array}{l}\text { Multi Layer } \\
\text { PerceptronNeural } \\
\text { Network based scheme }\end{array}$ & - & $1 / 4$ of data & $\begin{array}{l}3 / 4 \text { of } \\
\text { data }\end{array}$ & $\begin{array}{l}96.85 \% \\
\text { (isolated } \\
\text { strokes) } \\
88.23 \% \\
\text { (character) }\end{array}$ \\
\hline $\begin{array}{l}\text { Sumanta } \\
\text { Daw } \\
\text { et al.[24] } \\
(2013) \\
\end{array}$ & $\begin{array}{l}\text { Online } \\
\text { Handwritten } \\
\text { Compound } \\
\text { Words } \\
\end{array}$ & Segmentation & $\begin{array}{l}\text { Point Based Features }(90), \\
\text { Structural features }(15), \\
\text { Directional Features(128) }\end{array}$ & $\begin{array}{l}\text { Multilayer perception } \\
\text { NeuralNetwork Based } \\
\text { Scheme }\end{array}$ & - & - & $\begin{array}{l}4200 \\
\text { Compou } \\
\text { nd } \\
\text { Words } \\
\end{array}$ & $73 \%$ \\
\hline
\end{tabular}

Online Bangla word recognition system was built using Open-Source development environment ESMERALDA by Fink et al. [20]. Sub-Stroke Level Features and Hidden Markov Models are used for recognition. A quite satisfactory recognition rate of more than $93 \%$ is achieved. HMM Based Online Handwritten Bangla Character Recognition using Dirichlet Distributions was developed by Biswaset al. [21]. The character level recognition accuracy of $91.85 \%$ is reported.

Roy et al. [22] has proposed a Multi Layer Perception Neural Network based system for recognition of online handwritten Bangla characters. The sequential and dynamical information obtained from the pen movements on the writing pads is used as features in system. Features computed from the strokes are fed to the MLP classifier for recognition. The recognition rate of $96.85 \%$ for isolated strokes and $88.23 \%$ for overall system is reported.

A system for Stroke Segmentation and Recognition for Bangla Online Handwritten Text is given by Bhattacharya et al. [23]. Directional features were used in SVM for recognition and correct stroke recognition rate of $97.68 \%$ is reported. Sumanta et al. [24] has presented a system for online Bangla handwritten compound word recognition based on segmentation of word into its constituent characters. Segmentation rate of $87 \%$ and the overall recognition rate of $73 \%$ is reported.

Rajib et al. [25] has proposed a technique for segmentation of Online Bangla handwritten word by extracting basic features of different strokes as well as basic features of writing style of handwriting. Also another approach of Segmentation of Online Bangla Handwritten Word using busy zone concept has been proposed to segment Online Bangla handwritten word into its constituent basic strokes.

Table 3 gives an overview of the online handwritten recognition systems for Bangla characters.

\subsection{Recognition of Tamil Script}

Tamil is a popular classical language used by a significant population in South East Asian Countries. Joshi et al. [27] introduced a Tamil Handwriting Recognition system using Subspace and DTW based Classifiers. They compared both methods in writer dependent, independent and adaptive scenarios. Error rate of $11.15 \%$ (PCA) and $8.52 \%(\mathrm{DTW})$ in writer independent, 5.23\%(PCA) and 3.30\%(DTW) in writer dependent, and $5.41 \%$ (PCA) and $3.60 \%$ (DTW)is reported in writer adaptive testing. 
Table 4. Existing Tamil Online Handwritten Character Recognition System

\begin{tabular}{|c|c|c|c|c|c|c|c|c|}
\hline Author & Input & Pre-processing & Features & Method & Post_Processing & $\begin{array}{l}\text { Training } \\
\text { Set }\end{array}$ & Test Set & $\begin{array}{l}\text { Recognition } \\
\text { Rate }\end{array}$ \\
\hline $\begin{array}{l}\text { N. Joshi, } \\
\text { G. Sita } \\
\text { et al.[27] } \\
(2004)\end{array}$ & $\begin{array}{l}\text { Online } \\
\text { Handwritten } \\
\text { Character }\end{array}$ & $\begin{array}{l}\text { Smoothing, } \\
\text { Nomalization }\end{array}$ & $\begin{array}{l}\text { Pre processed } x, y \\
\text { coordinates are used as } \\
\text { feature for recognition }\end{array}$ & $\begin{array}{l}\text { Subspacebase } \\
\text { classification, } \\
\text { DTW Based } \\
\text { Classification }\end{array}$ & - & $\begin{array}{l}19440 \\
\text { samples }\end{array}$ & $\begin{array}{l}4860 \\
\text { samples }\end{array}$ & $\begin{array}{l}\text { Error Rate } \\
11.15 \%(\text { PCA } \\
), 8.52 \% \\
\text { (DTW) }\end{array}$ \\
\hline $\begin{array}{l}\text { Apama } \\
\text { et al.[28] } \\
(2004)\end{array}$ & $\begin{array}{l}\text { Online } \\
\text { Character } \\
\text { Data }\end{array}$ & $\begin{array}{l}\text { Interpolation, } \\
\text { Smoothing and } \\
\text { Nomalization }\end{array}$ & $\begin{array}{l}\text { Set of } 18 \text { Shape } \\
\text { Features }\end{array}$ & $\begin{array}{l}\text { Shape Feature } \\
\text { database, Rule } \\
\text { List, Finite State } \\
\text { Automation }\end{array}$ & - & - & - & $\mathrm{NA}^{*}$ \\
\hline $\begin{array}{l}\text { Toselli } \\
\text { et al.[29] } \\
(2007)\end{array}$ & $\begin{array}{l}\text { Online } \\
\text { Handwritten } \\
\text { Character }\end{array}$ & $\begin{array}{l}\text { Repeated Point } \\
\text { Elimination, } \\
\text { Noise Reduction } \\
\text { Speed and Size } \\
\text { Nomalization }\end{array}$ & $\begin{array}{l}\text {-Set of } 7 \text { Time Domain } \\
\text { Features, } \\
\text {-Set of } 8 \text { Frequency } \\
\text { Domain Features }\end{array}$ & HMM's & - & $\begin{array}{l}39618 \\
\text { Samples }\end{array}$ & $\begin{array}{l}26926 \\
\text { Samples }\end{array}$ & $\begin{array}{l}\text { Error Rate } \\
9.3 \%\end{array}$ \\
\hline $\begin{array}{l}\text { Swehta } \\
\text { Lakshami } \\
\text { et al.[7] } \\
(2008)\end{array}$ & $\begin{array}{l}\text { Online } \\
\text { Handwritten } \\
\text { Strokes }\end{array}$ & $\begin{array}{l}\text { Nomalization } \\
\text { Smoothing, } \\
\text { Interpolation }\end{array}$ & $\begin{array}{l}\text { Spatiotemporal } \\
\text { features,, } \\
\text { Spectral Features, } \\
\text { Spatiostructural } \\
\text { Features }\end{array}$ & $\begin{array}{l}\text { Support Vector } \\
\text { machine }\end{array}$ & $\begin{array}{l}\text { Disambiguation and } \\
\text { Regroupping }\end{array}$ & $\begin{array}{l}19398 \\
\text { Examples }\end{array}$ & $\begin{array}{l}9048 \\
\text { example } \\
\text { s }\end{array}$ & $\begin{array}{l}90.77 \% \text { (Spat } \\
\text { iostructural), } \\
91.92 \% \text { (Spat } \\
\text { iotemporal) }\end{array}$ \\
\hline $\begin{array}{l}\text { Rituraj } \\
\text { Kunwar } \\
\text { et al.[30] } \\
(2009)\end{array}$ & $\begin{array}{l}\text { Online } \\
\text { Handwritten } \\
\text { Words }\end{array}$ & $\begin{array}{l}\text { Smoothing, } \\
\text { Nomalization, } \\
\text { Resmapling }\end{array}$ & $\begin{array}{l}\text { Nomalized } x, y 1^{\text {tz }} \\
\text { Derivatives, } \\
\text { Normalized } x, y 2^{\text {as }} \\
\text { denvatives, Curvature }\end{array}$ & HMM & - & - & - & $\begin{array}{l}84 \% \text { (at } \\
\text { symbol } \\
\text { level) }\end{array}$ \\
\hline $\begin{array}{l}\text { Suresh } \\
\text { Sundaram } \\
\text { et al.[32] } \\
(2009)\end{array}$ & $\begin{array}{l}\text { Online } \\
\text { Handwritten } \\
\text { Character }\end{array}$ & $\begin{array}{l}\text { Smoothing, } \\
\text { Dehooking, } \\
\text { Resampling, } \\
\text { Nomalization }\end{array}$ & $\begin{array}{l}\text { Normalizedx,y } \\
\text { coordinates of points, } \\
\text { Distance, Angle, } \\
\text { Length, Position of } \\
\text { sample point with } \\
\text { respect to its } \\
\text { neighbours. }\end{array}$ & $\begin{array}{l}\text { NN+2DPAC } \\
\text { Classifier }\end{array}$ & Disambiguation & $\begin{array}{l}270 \\
\text { training } \\
\text { samples } \\
\text { for each } \\
\text { character }\end{array}$ & $\begin{array}{l}26926 \\
\text { random } \\
\text { Samples }\end{array}$ & $\begin{array}{l}86.5 \% \\
87.5 \% \text { (with } \\
\text { post- } \\
\text { processing) }\end{array}$ \\
\hline $\begin{array}{l}\text { Bhargava } \\
\text { Urala et } \\
\text { al.[34] } \\
(2013)\end{array}$ & $\begin{array}{l}\text { Online } \\
\text { Handwritten } \\
\text { Words }\end{array}$ & $\begin{array}{l}\text { Smoothing, } \\
\text { Nomalization, } \\
\text { Resampling }\end{array}$ & $\begin{array}{l}\mathrm{X}, \mathrm{y} \text { coordinates of } \\
\text { Normalised Symbols } \\
\text { and their first } \\
\text { derivatives as Local } \\
\text { Features, Truncated } \\
\text { Fourier Coefficients as } \\
\text { global features }\end{array}$ & $\begin{array}{l}\text { SVM with Radial } \\
\text { Basic } \\
\text { Function(RBF) }\end{array}$ & $\begin{array}{l}\text { Nbest choices of } \\
\text { symbol for a given } \\
\text { word are generated } \\
\text { using Viterbi Lattice, } \\
\text { String is then } \\
\text { converted to Unicode } \\
\text { stringusing FST. }\end{array}$ & - & - & $\mathrm{NA}^{*}$ \\
\hline
\end{tabular}

*NA: Not Available - Recognition result is not given in the terms of numeric value

A system for Online Recognition of Handwritten Tamil characters is presented by Aparna et al. [28]. Shape feature database, Rule list and Finite State Automata are used for character recognition. Work on On-Line Handwriting Recognition System for Tamil Handwritten Characters is reported by Toselli et al. [29]. The system is based on continuous density Hidden Markov Models and characterized time and frequency domain feature extraction. $10.0 \%$ classification error rate for 16 Gaussian densities is the best result reported. As discussed earlier, Swethalakshmi et al. [7], proposed a stroke based HCR systems, which use SVMs for stroke classification and a rule based approach for character identification, for two major Indian writing systems, Devanagari and Tamil. Classification accuracy of $91.92 \%$ for spatiotemporal, $92.13 \%$ for spectral, and $90.77 \%$ for spatiostructural features is obtained for Tamil script. Also post processing steps: Disambiguation and Regrouping are performed to resolve the ambiguities among confusable strokes and to identify non-proximal units. Kunwar at al. [30] developed HMM Based Online Tamil Word Recognizer where, Each Tamil symbol is modeled using a separate HMM. Training of the models is performed using the Baum Welch Estimation. The Bayesian approach is adopted for recognizing the label for the test symbol. An accuracy of $84 \%$ at the symbol level is reported. Kunwar et al. [31] have also present a fractal coding method to recognize online handwritten Tamil characters and proposed a novel technique to increase the efficiency in terms of time. This technique exploits the redundancy in data, thereby achieving better compression and usage of lesser memory. A recognition accuracy of $90 \%$ has been reported by using DTW as compared to $78 \%$ using nearest neighbour classifier. Sundaram et al. [32] have proposed a script-specific post processing schemes for improving the recognition rate of online Tamil characters. At the first level, features derived at each sample point of the preprocessed character are used to construct a subspace using the 2DPCA algorithm. Recognition of the test sample is performed using nearest neighbour classifier. Based on the analysis of the confusion matrix, multiple pairs of confused characters are identified. At the second level, script specific cues are used to sort out the ambiguities among the confused characters. Recognition accuracy of $86.5 \%$ is achieved using 2DPCA+NN classifier, however with the post-processing scheme the performance is improved by approximately $1 \%$. Also, they have proposed a Bigram language model and re-evaluation strategy for improved recognition of online handwritten Tamil words with recognition accuracies of $93.0 \%$ at the symbol and $81.6 \%$ at word level [33]. A system for Identification of Tamil script on Tablet PC is proposed by Urala et al. [34]. They used support vector 
machine with radial basis function (RBF) as kernel. In post processing, statistics of co-occurrence of Tamil symbols estimated from the Emille corpus of Tamil text along with SVM confidence levels are used to generate $\mathrm{N}$-best choices of symbol strings for a given handwritten word, using a Viterbi lattice. The symbol string is then converted to a Unicode string using a finite state transducer. Table 4 gives an overview of the online handwritten recognition systems for Tamil characters.

\subsection{Recognition of Telugu Script}

Telugu script is used by 100 million population in southern part of India. Rao et al. [35] have presented a system for online recognition of Telugu characters. In this approach, Individual strokes are identified by comparing the unknown stroke with a database of strokes. Combinations of strokes are then mapped onto ISCII codes of Telugu Characters.

Table 5. Existing Telgu Online Handwritten Character Recognition System

\begin{tabular}{|c|c|c|c|c|c|c|c|c|}
\hline Author & Input & Pre-processing & Features & Method & $\begin{array}{l}\text { Post__ } \\
\text { Processing }\end{array}$ & $\begin{array}{l}\text { Trainin } \\
\text { g Set }\end{array}$ & Test Set & $\begin{array}{l}\text { Recognition } \\
\text { Rate }\end{array}$ \\
\hline $\begin{array}{l}\text { Lakshami } \\
\text { et al.[36] } \\
(2006)\end{array}$ & $\begin{array}{l}\text { Online } \\
\text { Handwritten } \\
\text { Strokes }\end{array}$ & $\begin{array}{l}\text { Normalization, } \\
\text { Smoothing, } \\
\text { Interpolation }\end{array}$ & Coordinates of Points, Curve Length & SVM & - & $\begin{array}{l}33726 \\
\text { samples }\end{array}$ & $\begin{array}{l}4091 \\
\text { samples }\end{array}$ & $\mathrm{NA}^{*}$ \\
\hline $\begin{array}{l}\text { Prasanth } \\
\text { et al.[37] } \\
(2007)\end{array}$ & $\begin{array}{l}\text { Online } \\
\text { Handwritten } \\
\text { Symbols }\end{array}$ & $\begin{array}{l}\text { Resampling, } \\
\text { Nomalization }\end{array}$ & $\begin{array}{l}\text { Pre-Prosessed } \mathrm{x} \text { y Features, Shape } \\
\text { Context Features, Tangent Angle } \\
\text { Features, Generalised Shape Context } \\
\text { Features, Normalised Derivative } \\
\text { Features, Curvature Features. }\end{array}$ & $\begin{array}{l}\text { Elastic } \\
\text { Matching with } \\
\text { Local Features }\end{array}$ & - & $\begin{array}{l}29174 \\
\text { samples }\end{array}$ & $\begin{array}{l}9215 \\
\text { samples }\end{array}$ & $\begin{array}{l}87.22 \text { (with } \\
\text { L7 features) }\end{array}$ \\
\hline $\begin{array}{l}\text { Babu and } \\
\text { Prasanth } \\
\text { et al.[38] } \\
(2007)\end{array}$ & $\begin{array}{l}\text { Online } \\
\text { Handwritten } \\
\text { Symbols }\end{array}$ & $\begin{array}{l}\text { Duplicate Point } \\
\text { Elimination, } \\
\text { Smoothing, } \\
\text { Size } \\
\text { Normalization, } \\
\text { Resampling }\end{array}$ & $\begin{array}{l}\text { Time Domain Features, Frequency } \\
\text { Domain Features }\end{array}$ & HMM & - & $\begin{array}{l}29158 \\
\text { training } \\
\text { samples }\end{array}$ & $\begin{array}{l}9235 \\
\text { Test } \\
\text { Sample }\end{array}$ & $\begin{array}{l}91.6 \% \text { (Top } \\
1 \text { accuracy) } \\
98.7 \% \text { (top } 5 \\
\text { accuracy) }\end{array}$ \\
\hline $\begin{array}{l}\text { Amit } \\
\text { Arora } \\
\text { et al.[39] } \\
(2010)\end{array}$ & $\begin{array}{l}\text { Online } \\
\text { Handwritten } \\
\text { Strokes }\end{array}$ & $\begin{array}{l}\text { Normalization, } \\
\text { Resampling }\end{array}$ & $\begin{array}{l}\text { Rawx,y Coordinates of resampled } \\
\text { points, Moments of strokes, Overall } \\
\text { direction and Curvature of Stroke } \\
\text { Length of the Stroke, Aspect Ratio, } \\
\text { Area of Stroke, Number and } \\
\text { Direction of points in different sub } \\
\text { windows, projection histograms, } \\
\text { Fourier coefficients of } x, y \text { sequences }\end{array}$ & $\begin{array}{l}\text { SVM classifier } \\
\text { using a } \\
\text { DDAG(Decisio } \\
\text { n Directed } \\
\text { Acyclic Graph), } \\
\text { Discriminating } \\
\text { classifier }\end{array}$ & $\begin{array}{l}\text { Akshara } \\
\text { recognizer } \\
\text { using } \\
\text { FSA(Finite } \\
\text { State } \\
\text { Automation } \\
\text { ) }\end{array}$ & $\begin{array}{l}57669 \\
\text { samples }\end{array}$ & - & $\begin{array}{l}75.70 \% \\
\text { (telgu) }\end{array}$ \\
\hline $\begin{array}{l}\text { KVijay } \\
\text { Kumar } \\
\text { et al.[40] } \\
(2013)\end{array}$ & $\begin{array}{l}\text { Online } \\
\text { Handwritten } \\
\text { Character }\end{array}$ & $\begin{array}{l}\text { Binarization, } \\
\text { Smoothing and } \\
\text { Noise Removal, } \\
\text { Normalization, } \\
\text { Thinning, } \\
\text { Segmentation, } \\
\text { Skew } \\
\text { Detection, } \\
\text { Slant } \\
\text { Correction } \\
\end{array}$ & $\begin{array}{l}\mathrm{x}, \mathrm{y} \text { coordinate points, Fourier } \\
\text { Transforms, Hilbert transform } \\
\text { logarithm of spectral density, } \\
\text { Wavelet Features }\end{array}$ & SVM & - & & - & $96.69 \%$ \\
\hline
\end{tabular}

*NA: Not Available - Recognition result is not given in the terms of numeric value

Swethalakshmi et al. [36] developed a system for Online Handwritten Character Recognition of Devanagari and Telugu Characters. Support vector machines have been used for constructing the stroke recognition engine. System for Online Handwritten Tamil and Telugu Scripts is presented by Prasanth et al. [37] using Elastic matching with local features. Nearest neighbour classifier with DTW distance was used as the classifier. For Telugu data an accuracy of $87.22 \%$ is reported using L7 features.

HMM-based Online Handwriting Recognition System for Telugu Symbols is developed by Babu et al. [38]. They introduced a cost-effective and natural data collection procedure based on ACECAD Digimemo. The combination of time-domain and frequency domain features is used in the system. Top-1 accuracy of $91.6 \%$ and top-5 accuracy of $98.7 \%$ on a dataset containing 29,158 train samples and 9,235 test samples is reported. A Hybrid Model for Recognition of Online Handwriting for two Indian Scripts, Telugu and Malayalam is presented by Arora et al. [39]. The recognition is based on a generative model of handwriting formation, coupled with a discriminative model for classification of strokes. In post processing akshara recognizer using FSA is used to estimate the most likely sequence of aksharas. For telugu data set word level accuracy of $75.70 \%$ is reported.

Kumar et al. [40] have presented a system for Online Handwritten Character Recognition for Telugu Language Using Support Vector Machines. Overall stroke recognition accuracy of $96.69 \%$ is reported. Table 5 gives an overview of the online handwritten recognition systems for Telugu characters. 
Gujarati language is used in the western state of Gujarat. Because of script peculiarities, Character Recognition becomes difficult. Character Recognition of Gujarati script becomes difficult because of lack of use of "Shirolekha". Like many Indian languages, many modifiers are used in Gujarati, and sometimes these modifiers change even the shape of the basic alphabet. Very less work has been done in the area of Optical Character Recognition for Guajarati Language. However, online handwritten character recognition for Gujarati language remained untouched.

\subsection{Recognition of Kannada Script}

Kannada is one of the scheduled languages of India and the official language of the South Indian state of Karnataka. The recognition of isolated Kannada characters was first introduced by Kunte et al. [41]. Wavelet feature extracted from the character contour and Multi-layer feedforward neural networks with a single hidden layer are used for recognizing the characters.

Table 6. Existing Kannada Online Handwritten Character Recognition System

\begin{tabular}{|c|c|c|c|c|c|c|c|c|}
\hline Author & Input & $\begin{array}{l}\text { Pre- } \\
\text { processing }\end{array}$ & Features & Method & $\begin{array}{l}\text { Post- } \\
\text { Processing }\end{array}$ & $\begin{array}{l}\text { Training } \\
\text { Set }\end{array}$ & Test Set & Recognition Rate \\
\hline $\begin{array}{l}\text { Parsad } \\
\text { et al.[42] } \\
(2009)\end{array}$ & $\begin{array}{l}\text { Online } \\
\text { Handwritten } \\
\text { Data }\end{array}$ & $\begin{array}{l}\text { Noise } \\
\text { removal, } \\
\text { Resampling, } \\
\text { Nomalization } \\
\end{array}$ & $\begin{array}{l}\text { Size Normalized } \\
\text { Horizontal and Vertical } \\
\text { Coordinates }\end{array}$ & $\begin{array}{l}\text { Divide and } \\
\text { Conquer for } \\
\text { segmentation, K- } \\
\text { NN Classifier }\end{array}$ & - & $\begin{array}{l}11952 \\
\text { samples }\end{array}$ & $\begin{array}{l}5229 \\
\text { samples }\end{array}$ & $81 \%$ \\
\hline $\begin{array}{l}\text { Rituraj } \\
\text { Kunwar } \\
\text { et } \\
\text { al. }[43,44] \\
(2010)\end{array}$ & $\begin{array}{l}\text { Input } \\
\text { Handwritten } \\
\text { Character }\end{array}$ & $\begin{array}{l}\text { Nomalization } \\
\text {,Smoothing, } \\
\text { Arc Length } \\
\text { Resampling }\end{array}$ & $\begin{array}{l}\text { Pre-Processed } x, y \\
\text { Coordinates, } \\
1^{\text {: derivative of } x, y} \\
\text { coordinates (estimate } 1 \& \\
\text { estimate 2) }\end{array}$ & $\begin{array}{l}\text { Statistical } \\
\text { Dynamic Time } \\
\text { Wrapping(SDTW) }\end{array}$ & - & $\begin{array}{l}\text { Total } 295 \\
\text { classes } \\
\text { and } 40 \\
\text { samples } \\
\text { for each } \\
\text { class }\end{array}$ & $\begin{array}{l}29 \\
\text { samples } \\
\text { for each } \\
\text { class }\end{array}$ & $\begin{array}{l}85.2 \% \text { (estimate } 1) \\
87.9 \% \text { (estimate 2) }\end{array}$ \\
\hline $\begin{array}{l}\text { AG } \\
\text { Ramkrish } \\
\text { nan } \\
\text { et al.[46] }\end{array}$ & $\begin{array}{l}\text { Online } \\
\text { Handwritten } \\
\text { Symbol }\end{array}$ & $\begin{array}{l}\text { Smoothing, } \\
\text { Normalization } \\
\text {,Resampling }\end{array}$ & $\begin{array}{l}\text { Number of dominant } \\
\text { points, Inter Stroke } \\
\text { Features, Symbol Size, } \\
\text { Arc-length of Each } \\
\text { Stroke }\end{array}$ & SVM Classifier & - & - & $\begin{array}{l}44772 \\
\text { words }\end{array}$ & $\begin{array}{l}62 \% \text { (symbol } \\
\text { recognition) } \\
18.2 \% \text { (word } \\
\text { recognition) }\end{array}$ \\
\hline $\begin{array}{l}\text { MM } \\
\text { Parsad } \\
\text { et al.[47] } \\
(2013)\end{array}$ & $\begin{array}{l}\text { Online } \\
\text { Handwritten } \\
\text { Data }\end{array}$ & $\begin{array}{l}\text { Noise } \\
\text { removal, } \\
\text { Resampling, } \\
\text { Nomalization }\end{array}$ & $\begin{array}{l}\text { Normalizedx,y } \\
\text { coordinates, Trajectory } \\
\text { features, first derivative } \\
\text { feature, second denivative } \\
\text { features, deviation } \\
\text { features, Estimate } \\
\text { features }\end{array}$ & 2D-LDA & - & $\begin{array}{c}3750 \\
\text { samples }\end{array}$ & $\begin{array}{c}1550 \\
\text { samples }\end{array}$ & $86 \%$ to $88.3 \%$ \\
\hline
\end{tabular}

Prasad et al. [42] proposed Divide and Conquer Technique for Online Handwritten Kannada Character Recognition. The structural and the spatiotemporal information of handwritten Kannada characters are exploited to segment a compound character into three distinct stroke units. The subspace features of each class of stroke groups are fed to their respective nearest neighbour $(\mathrm{NN})$ classifiers for classification. The results from these classifiers are then combined to generate the output character. Maximum recognition accuracy attainable from the proposed system is around $81 \%$.

System for unrestricted Kannada online HCR is proposed by Kunwar et al. [43]. Statistical dynamic time warping (SDTW) has been employed to classify Kannada characters with $\mathrm{x}$-y coordinates of the trace and their first order derivatives as features. 46 times faster classification rate is achieved Using SDTW over DTW with comparable accuracy of $88 \%$. Kunwar et al. [44] also developed a system to perform recognition of entire word. Writer independent word level recognition of $80 \%$ is reported using SDTW as classifier with estimate 2 of first derivatives as features.

Online HCR system for Kannada using Principal Component Analysis Approach is proposed by Parsad et al. [45]. System is implemented on mobile device using two different approaches namely Principal Component Analysis (PCA) and Dynamic Time Wrapping (DTW), an average recognition accuracy of $88 \%$ for the PCA and up to 64\% is achieved for DTW approach. Ramakrishnan et al. [46] developed an online handwritten system for kannada characters. In addition to basic characters, 9 Kannada numerals, 9 Hindu Arabic numerals and 22 special symbols used in poetry, shlokas and Kannada grammar are also considered for recognition. AFS method is used to segment the online Kannada word into its constituent symbols.

2D-LDA based system for Online Handwritten Kannada Character Recognition is developed by Prasad et al. [47]. Feature combinations extracted from the size normalized characters are fed to 2D-LDA for dimensionality reduction and nearest neighbor classifier is used for classification. Reported average recognition accuracy varies between $86 \%$ and $88.3 \%$. Table 6 gives an overview of the online handwritten recognition systems for Kannada characters and numerals.

\subsection{Recognition of Malayalam Script}


Malayalam script is used by millions of people in the state of Kerala and in the Lakshadweep Islands. System for online recognition of handwritten Malayalam characters is presented by Shankar et al. [48]. Soft matching strings are used to recognize new characters.

Table 7. Existing Malayalam Online Hand written Character Recognition System

\begin{tabular}{|c|c|c|c|c|c|c|c|c|}
\hline Author & Input & Pre-processing & Features & Method & $\begin{array}{l}\text { Post__ } \\
\text { Processing }\end{array}$ & $\begin{array}{l}\text { Training } \\
\text { Set }\end{array}$ & $\begin{array}{l}\text { Test } \\
\text { Set }\end{array}$ & $\begin{array}{l}\text { Recognition } \\
\text { Rate }\end{array}$ \\
\hline $\begin{array}{l}\text { Gowari } \\
\text { Shankar } \\
\text { et al.[48] } \\
(2003)\end{array}$ & $\begin{array}{l}\text { Online } \\
\text { Character } \\
\text { Data }\end{array}$ & $\begin{array}{l}\text { Normalization and } \\
\text { Smoothing of } \\
\text { strokes }\end{array}$ & $\begin{array}{l}\text { A set of } 8 \text { Shape Based Features } \\
\text { is Used }\end{array}$ & $\begin{array}{l}\text { String Matching } \\
\text { Algorithm }\end{array}$ & - & & - & $\begin{array}{l}90.75 \% \\
\text { approx. } \\
\text { (for } 4 \text { data } \\
\text { sets) }\end{array}$ \\
\hline $\begin{array}{l}\text { Amit } \\
\text { Arora et } \\
\text { al.[39] } \\
(2010)\end{array}$ & $\begin{array}{l}\text { Online } \\
\text { Handwritten } \\
\text { Strokes }\end{array}$ & $\begin{array}{l}\text { Normalization, } \\
\text { Resampling }\end{array}$ & $\begin{array}{l}\text { Raw x,y Coordinates of } \\
\text { resampled points, Moments of } \\
\text { strokes, Overall direction and } \\
\text { Curvature of Stroke Length of the } \\
\text { Stroke, Aspect Ratio, Area of } \\
\text { Stroke, Number and Direction of } \\
\text { points in different sub windows, } \\
\text { projection histograms, Fourier } \\
\text { coefficients of x,y sequences. }\end{array}$ & $\begin{array}{l}\text { SVM classifier } \\
\text { using a } \\
\text { DDAG(Decision } \\
\text { Directed Acyclic } \\
\text { Graph), } \\
\text { Discriminating } \\
\text { classifier }\end{array}$ & $\begin{array}{l}\text { Akshara } \\
\text { recognizer } \\
\text { using } \\
\text { FSA(Finite } \\
\text { State } \\
\text { Automation) }\end{array}$ & $\begin{array}{c}7348 \\
\text { samples }\end{array}$ & - & $\begin{array}{l}78.07 \% \\
\text { (malayalam) }\end{array}$ \\
\hline $\begin{array}{l}\text { Seeraj M } \\
\text { et al.[49] } \\
(2010)\end{array}$ & $\begin{array}{l}\text { Writer } \\
\text { Independent } \\
\text { Handwritten } \\
\text { Character }\end{array}$ & $\begin{array}{l}\text { Dot detection, } \\
\text { Dehooking, } \\
\text { Smoothing, } \\
\text { Thinning, Loop } \\
\text { Detection, } \\
\text { Normalization, } \\
\text { Equidistant } \\
\text { Resampling }\end{array}$ & $\begin{array}{l}\text { Time Domain Features, } \\
\text { Directional Features, } \\
\text { Curvature }\end{array}$ & $\begin{array}{l}\text { Nearest Neighbour } \\
\text { Classifier(K-NN) }\end{array}$ & - & $\begin{array}{l}2591 \\
\text { samples }\end{array}$ & - & $98.125 \%$ \\
\hline $\begin{array}{l}\text { R. } \\
\text { Ravinder } \\
\text { Kumar } \\
\text { et al.[50] } \\
\text { (2011) }\end{array}$ & $\begin{array}{l}\text { Online } \\
\text { Handwritten } \\
\text { Character }\end{array}$ & $\begin{array}{l}\text { Dehooking, size } \\
\text { Normalization, } \\
\text { Resampling, } \\
\text { Smoothing and } \\
\text { Removal of } \\
\text { Duplicate points }\end{array}$ & $\begin{array}{l}\text { Geometric Features, Ink related } \\
\text { Features, Directional Features, } \\
\text { Global Features, Local Features }\end{array}$ & Elastic Matching & $\begin{array}{l}\text { Stroke } \\
\text { correction, } \\
\text { Stroke } \\
\text { Concatinatio } \\
\text { n, Linguistic } \\
\text { Rules }\end{array}$ & & - & $\begin{array}{l}82 \% \text { (at } \\
\text { word level) } \\
94 \% \text { (at } \\
\text { character } \\
\text { level) }\end{array}$ \\
\hline $\begin{array}{l}\text { Amritha } \\
\text { Sampath } \\
\text { et al.[51] } \\
(2012)\end{array}$ & $\begin{array}{l}\text { Online } \\
\text { Handwritten } \\
\text { Character }\end{array}$ & Noise Removal & $\begin{array}{l}\text { Low level Features(width, height, } \\
\text { curliness, aspect ratio), High } \\
\text { Level Features (number and } \\
\text { position of loops, straight lines, } \\
\text { headlines, curves), Directional } \\
\text { Features }\end{array}$ & $\begin{array}{l}\text { Back Propagation } \\
\text { Neural Network }\end{array}$ & $\begin{array}{l}\text { Representati } \\
\text { on of output } \\
\text { in Unicode } \\
\text { formate, } \\
\text { Disambiguati } \\
\text { on of } \\
\text { confusing } \\
\text { paires }\end{array}$ & & - & $\begin{array}{l}\text { ctivate Wi } \\
\text { o to Settings }\end{array}$ \\
\hline
\end{tabular}

*NA: Not Available - Recognition result is not given in the terms of numeric value

As discussed earlier, Online HCR system for two Indian Scripts, Telugu and Malayalam is presented by Arora et al. [38]. The recognition is based on a generative model of handwriting formation, coupled with a discriminative model for classification of strokes. In post processing akshara recognizer using FSA is used to estimate the most likely sequence of aksharas. For Malayalam data set word level accuracy of $78.07 \%$ is reported.

Sreeraj et al. [49] presented k-NN based On-Line Handwritten Character recognition system. A novel feature extraction method, a combination of time domain features and dynamic representation of writing direction along with its curvature is used for recognizing Malayalam characters. This writer independent system gives an accuracy of $98.125 \%$ with recognition time of $15-30$ milliseconds.

Online handwriting recognition system for Malayalam using elastic matching technique is presented by Kumar et al. [50]. Two-stage classification scheme using nearest neighbour classifier is adopted. Post processing steps 1) Stroke correction 2) Stroke concatenation 3) Linguistic rules are performed to improve the recognition accuracy. The post processing stage also makes use of a spellchecker to identify the word written is valid or not. For invalid words, suggestions from the dictionary are provided. With DTW- classifier and spellchecker, an average recognition rate of $94 \%$ at character level and $82 \%$ at word level is reported. Sampath et al. [51] presented a Neural Network based model for handwritten character recognition. Back propagation Neural Network is used for classification of characters. Additional disambiguation technique is used in post processing stage to identify confusing pairs. Table 7 gives an overview of the online handwritten recognition systems for Malayalam characters.

\subsection{Recognition of Oriya Script}

Oriya script is used to write the Oriya language which is spoken in Odisha state situated in the eastern part of India. During the last decades, intensive research studies have been made for recognition of handwritten characters and numerals in various Indian and foreign languages, but a few work has been reported on Oriya character recognition. Few literatures available for printed and offline handwritten character recognition but, no work has been done on online handwritten character recognition. The field of character recognition in Oriya language still needs an in depth study. Researchers tried to explore the possibilities of directional, structural, 
zonal, statistical topological, morphological, wavelet features. The majority of the researchers have used neural network, K-NN and SVM, MLP, PCA, Fuzzy, Binary Tree, LDA, HMM, DTW based classifiers. There is lack of availability of benchmarking databases for research. From the literature, it is clear that many of the researchers have used their own databases for evaluating their techniques. So it is very difficult to compare the various techniques and methods proposed by the researchers.

\section{Challenges Of Online Hcr}

Recognition of handwritten Indian scripts is difficult because of the presence of numerals, vowels, consonants, vowel modifiers and compound characters. The structure of the scripts and the variety of shapes and writing styles pose challenges that are different from other scripts and hence require customized techniques for feature representation and recognition [3]. The Online Handwriting recognition for Indian scripts is a greater challenge because of the following reasons:

- The structure of the scripts and the variety of shapes. The same character may take different shapes and two or more character may take a similar shape.

- Presence of large number of characters.

- Handwriting style variations, Handwritings vary from person to person and also for a person it may vary from time to time according to his/her mood, urgency, etc.

- Two-Dimensional Structure of scripts, in most Indian scripts matras or vowels diacritics occurs to left, right, bottom, top or even as multiple components around the base consonant.

- Complexity of the characters \& Inter-class Similarity

- Poor reliability of extracted stroke features due to variance in handwriting

- Due to limitations of the device or speed of writing, it is possible for a single character to be broken into different parts, hence creating confusion in recognition.

Challenging problems in online hand writing recognition are different character sizes, stroke number/order variation and duplicate pixels produced by hesitation in writing or interpolated non-adjacent pixels caused by fast writing [53]. Vocabulary is also a major factor in determining the difficulty of handwriting recognition task. (i) Closed-vocabulary tasks refer to recognition of words from a predetermined dictionary; (ii) Open-vocabulary tasks refer to recognition of any words without the constraint of being in a dictionary. Closedvocabulary tasks are easier than open-vocabulary ones because only certain sequences of letters are possible when limited by a dictionary [15]. There are several other script dependent issues, for example, Malayalam text is written mostly in clockwise direction and consists of loops and curves, presence of shape modifiers in Gujarati etc. Most recent progress in this concern has been made either through improved pre-processing or through advances in language modeling. Relatively little work has been done in the development of basic recognition algorithms, in depth study needed in concern.

\section{Scope And Future Work}

The work reported on Online HCR for Indian scripts may be extended in various directions. Some of them are listed below:

- Little (or no) Literature is available for Online HCR system for Oriya and Gujarati scripts, the task of script identification can be explored.

- Extension of online handwriting recognition to the recognition of large or very large vocabularies.

- Spelling and semantic checks can be incorporated to correct error at stroke, character and word level.

- Widening of the domain from on-line handwriting recognition systems to the composition of on-line composite documents containing handwriting, graphics, drawings and symbols.

- Incremental learning can be incorporated so that a new stroke or character can be incorporated without the requirement of retraining the entire system.

- Development of bilingual and multi lingual online HCR.

- Ink management in documents, i.e. edition of documents by graphic gestures, annotation of documents.

- Idea of on-line construction and understanding of composite documents.

- Online Handwritten character recognition for Mobile devices.

Recently, interest has occurred concerning the biometric applications of online handwriting, namely for writer authentication and signature verification. Recognition of unconstrained handwriting with openvocabulary is clearly the end objective of Online HCR research.

\section{Conclusion}

In this paper work on Online HCR for Indian Scripts paper has been summarized. Majority of the research work reported for Indian languages either dealt with a subset of characters such as only the base characters or approaches based on limited vocabulary lexicon based recognizers. Although much research in the 
field of HCR has been done, recognition algorithms still do not achieve 100\% of the high recognitions. Many of the researchers do research for a short period of time as a part of their academic courses. As a result there is a great amount of redundancy in the work related to Indian script OHR. The above discussed approaches have their own applicability, but they are having limited domain.

\section{References}

[1] U. Pal, B.B. Chaudhuri, "Indian Script character recognition: a survey", Pattern Recognition 37, pp. 1887-1899, 2004.

[2] Soumen Bag, Gaurav Harit, "A survey on optical character recognition for Bangla and Devanagari scripts", Indian Academy of Sciences, pp. 133-168, 2013.

[3] A. Bharath, Sriganesh Madhvanath, "Online Handwriting Recognition for Indic Scripts", Guide to OCR for Indic Scripts, Advances in Pattern Recognition, Springer-Verlag London, pp. 209-234, 2010.

[4] Eric Anquetil and Guy Lorette, "New Advances and New Challenges in On-Line Handwriting Recognition and Electronic Ink Management", Digital Document Processing, Advances in Pattern Recognition, Springer-Verlag London, pp. 143-164, 2007.

[5] S. D. Connell, R. M. K. Sinha and A. K. Jain, "Recognition of unconstrained online Devanagari characters", Proceedings of International Conference on Pattern Recognition, vol. 2, pp. 368-371, 2000.

[6] N. Joshi,G. Sita, A.G Ramakrishnan, Deepu V., and Sriganesh Madhvanath, "Machine recognition of online handwritten Devanagari characters", Proceedings of International Conference of Document Analysis and Recognition, pp. 1156-1160, 2005.

[7] H. Swethalakshmi, "Online Handwritten Character Recognition for Devanagari and Tamil scripts using Support Vector Machines", Master of Science Thesis, Department of Computer Science and Engineering, Indian Institute of Technology, Madras, 2008.

[8] Bhushan C. Bhokse, Bhushan S.Thakare, "Devnagari Handwriting Recognition System using Dynamic Time Warping Algorithm", International Journal of Computer Applications, pp. 7-13, 2012.

[9] Deepika Wadhwa, "Recognition of Online Handwritten Devanagari Numerals using Support Vector Machine", Master of Engineering Thesis, Computer Science and Engineering Department, Thapar University, Patiala, 2012.

[10] Sharuti Kabatur, "Online Devanagari Handwritten Character Recognition”, Master of Applied Science Thesis, University of Windsor, Ontario, Canada, 2012.

[11] Anuj Sharma , "Online Handwritten Gurmukhi Character Recognition", Doctor of Philosophy Thesis, School of Mathematics and Computer Applications, Thapar University, Patiala, 2009.

[12] Manoj K. Sachan, Gurpreet Singh Lehal, Vijender Kumar Jain, “A System for Online Gurmukhi Script Recognition”, ICISIL, pp. 299-300, 2011

[13] Manoj K. Sachan, Gurpreet Singh Lehal, Vijender Kumar Jain, “A Novel Method to Segment Online Gurmukhi Script”, ICISIL, pp. $1-8,2011$.

[14] Shivali, "Recognition of Online Handwritten Punjabi Numerals", Master of Science Thesis, School of Mathematics and Computer Applications, University, Patiala, 2011.

[15] Rahul Agrawal, "Recognition of Online Handwritten Gurmukhi Stroke using Support Vector Machine", M.tech. Thesis, School of Mathematics and Computer Applications, Thapar University, Patiala, 2012.

[16] Dushyant Khurana , "Online Handwritten Gurmukhi Character Recognition using Support Vector Machine”, M.tech. Thesis, School of Mathematics and Computer Applications, Thapar University, Patiala, 2013.

[17] U. Bhattacharya, A. Nigam, Y. S. Rawat, S. K. Parui, "An Analytic Scheme for Online Handwritten Bangla Cursive Word Recognition", in the Proceedings of the International Conference on Frontiers in Handwriting Recognition (ICFHR 2008), Montreal, Canada, pp. 320 - 325, 2008.

[18] Asok Bandyopadhyay, "Online Handwritten Character Recognition System for Bangla", In: Proceedings of International Conference on Information Processing (ICIP-2008), Bangalore, pp. 170-179, 2008.

[19] S. K. Parui, K. Guin, U. Bhattacharya, B. B. Chaudhuri, "Online Handwritten Bangla Character Recognition using HMM", proceedings of $19^{\text {th }}$ International Conference on Pattern Recognition (ICPR 2008) published by IEEE Computer Society Press, pp.14. 2008.

[20] Gernot A. Fink, Szilard Vajda, Ujjwal Bhattacharya, Swapan K. Parui, Bidyut B. Chaudhuri, "Online BanglaWord Recognition Using Sub-Stroke Level Features and Hidden Markov Models", proceedings of $12^{\text {th }}$ International Conference on Frontiers in Handwriting Recognition(ICFHR 2010) published by IEEE Computer Society Press, pp.393-398, 2010.

[21] Chandan Biswas, Ujjwal Bhattacharya, Swapan Kumar Parui, "HMM Based Online Handwritten Bangla Character Recognition using Dirichlet Distributions", Proceedings of International Conference on Frontiers in Handwriting Recognition(ICFHR 2012) published by IEEE Computer Society Press, pp. 598-603, 2012.

[22] K. Roy, "Stroke Database Design for Online handwriting Recognition in Bangla", International Journal of Modern Engineering Research, Vol. 2, Issue 4, July-Aug. 2012, pp. 2534-2540, 2012.

[23] Nilanjana Bhattacharya, Umapada Pal (2012), "Stroke Segmentation and Recognition from Bangla Online Handwritten Text", Proceedings of International Conference on Frontiers in Handwriting Recognition(ICFHR 2012) published by IEEE Computer Society Press, pp. 736-741, 2012.

[24] Sumanta Daw, "Online Bangla Handwritten Compound Word Recognition Based On Segmentation”, ACER 2013, pp. 69-76, 2013.

[25] Rajib Ghosh, "Segmentation of Unconstrained Online Bangla Handwritten Word by Extracting Basic Features", International Conference on Advances in Communication, Network, and Computing (CNC 2010), Calicut, Kerala, pp. 296-298, 2010.

[26] Rajib Ghosh, "Segmentation of Online Handwritten Word by Estimating the Busy Zone of the Image", Proceedings of International Conference on Image Processing, Computer Vision, \& Pattern Recognition (IPCV'13), Las Vegas, USA, pp. 753-758, 2013.

[27] Niranjan Joshi, G. Sita, A.G. Ramakrishnan, Sriganesh Madhvanath, "Tamil Handwriting Recognition using Subspace and DTW based Classifiers", Proceedings of $11^{\text {th }}$ International Conference (ICONIP- 2004) published by Springer Berlin Heidelberg ,pp. 806$813,2004$.

[28] K.H. Aparna, Vidhya Subramanian, M. Kasirajan, G. Vijay Prakash, V.S. Chakravarthy, "Online handwriting recognition for Tamil", Proceedings of $9^{\text {th }}$ International Workshop on Frontiers in Handwriting Recognition (IWFHR-9 2004) published by IEEE Computer Society Press , pp. 438-443, 2004.

[29] Alejandro H. Toselli, Moises Pastor, Enrique Vidal, "On-Line Handwriting Recognition System for Tamil Handwritten Characters", Springer-Verlag Berlin Heidelberg, pp. 370-377, 2007.

[30] Rituraj Kunwar, Shashi Kiran, Suresh Sundaram, A G Ramakrishnan, “A HMM Based Online Tamil Word Recognizer", Proceedings of Conference on Tamil Internet (INFITT-2009), Cologne, Germany, pp. 165-168, 2009. 
[31] Rituraj Kunwar, A. G. Ramakrishnan, "Online handwriting recognition of Tamil script using Fractal geometry”, Proceedings of International Conference on Document Analysis and Recognition (ICDAR 2011) published by IEEE Computer Society press, pp. 1389-1393, 2011.

[32] Suresh Sundaram, A G Ramakrishnan, “An Improved Online Tamil Character Recognition Engine using Post-Processing Methods", Proceedings of $10^{\text {th }}$ International Conference on Document Analysis and Recognition(ICDAR 2009) published by IEEE Computer Society Press , pp. 1216-1220, 2009.

[33] Suresh Sundaram, A G Ramakrishnan, "Bigram language models and reevaluation strategy for improved recognition of online handwritten Tamil words", ACM Transactions on Asian Language Information Processing, 2014.

[34] Bhargava Urala and A G Ramakrishnan , "Identification of Tamizh script on Tablet PC", Proceedings of $12^{\text {th }}$ International Tamil Internet Conference, Kuala Lumpur, Malaysia, pp. 174-176, 2013.

[35] M. Srinivas Rao, Gowrishankar, V.S.Chakravarthy, "Online Recognition of Handwritten Telugu Characters", International Conference on universal knowledge and Language, Goa, India, 2002.

[36] H. Swethalakshmi, Anitha Jayaraman, V. Srinivasa Chakravarthy, C. Chandra Sekhar, "Online Handwritten Character Recognition of Devanagiri and Telugu Characters using Support Vector Machines", $10^{\text {th }}$ International Workshop on Frontiers in Handwriting Recognition (IWFHR 2006), La Baule, France, pp. 367-372, 2006.

[37] L.Prasanth, V.Jagadeesh Babu, R. Raghunath Sharma, G.V. Prabhakara Rao, Dinesh M, "Elastic Matching of Online Handwritten Tamil and Telugu Scripts using Local Features", Proceedings of $9^{\text {th }}$ International Conference on Document Analysis and Recognition, Washington, DC, USA, vol 2, pp. 1028-1032, 2007.

[38] V. Jagadeesh Babu, L. Prasanth, R. Raghunath Sharma, G.V. Prabhakara Rao, Bharath A, "HMM-Based online handwriting recognition system for Telugu symbols", Proceedings of $9^{\text {th }}$ International Conference on Document Analysis and Recognition(ICDAR 2007) published by IEEE Computer Society Press, vol 1, pp. 63-67, 2007.

[39] Amit Arora, Anoop M. Namboodiri, "A Hybrid Model for Recognition of Online Handwriting in Indian Scripts", Proceedings of International Conference on Frontiers in Handwriting Recognition (ICFHR-2010) published by IEEE, pp. 433-438, 2010.

[40] K. Vijay Kumar, R.Rajeshwara Rao, "Online Handwritten Character Recognition for Telugu Language Using Support Vector Machines”, International Journal of Engineering and Advanced Technology (IJEAT), vol. 3, pp. 189-192, 2013.

[41] S R Kunte, S Samuel (2000), "Wavelet Features based Online Recognition of Handwritten Kannada Characters", Journal Visualization Society of Japan, pp. 417-420, 2000.

[42] M. Mahadeva Prasad, M. Sukumar, A. G. Ramakrishnan, "Divide and Conquer Technique in Online Handwritten Kannada Character Recognition", In Proc. of the International Workshop on Multilingual OCR, Barcelona, Spain, pp. 1-7, 2009.

[43] Rituraj Kunwar, Mohan P., Shashikiran K, A. G. Ramakrishnan, "Unrestricted Kannada Online Handwritten Akshara Recognition using SDTW", Proceedings of International Conference on Signal Processing and Communications (SPCOM 2010) published by IEEE, pp. 1-5, 2010.

[44] Rituraj Kunwar, Shashikiran K, A. G. Ramakrishnan, "Online Handwritten Kannada Word Recognizer with Unrestricted Vocabulary", Proceedings of $12^{\text {th }}$ International Conference on Frontiers in Handwriting Recognition (ICFHR 2010) Published by IEEE, pp. 611-616, 2010.

[45] G Keerthi Prasad, I. Khan, N.R. Chanukotimath, F. Khan, "Online Handwritten Character Recognition System for Kannada using Principal Component Analysis Approach: for Handheld Devices", proceedings of World Congress on information and communication technologies (WICT 2012) published by IEEE, pp. 675-678, 2012.

[46] A G Ramakrishnan and J Shashidhar, "Development of OHWR System for Kannada", VishwaBharat@tdil, Vol. 39-40, pp. 67-95, 2013.

[47] M. Mahadeva Prasad and M. Sukumar, “2D-LDA based Online Handwritten Kannada Character Recognition”, International Journal of Computer Science and Telecommunications, vol. 4, pp. 14-18, 2013.

[48] Gowri Shankar, V. Anoop and V. S. Chakravarthy, "LEKHAK[MAL]: A System for Online Recognition of Handwritten Malayalam Character", Proceedings of NCC 2003, pp. 463-467, 2003.

[49] Sreeraj.M, Sumam Mary Idicula, "k-NN based On-Line Handwritten Character recognition system", Proceedings of $1^{\text {st }}$ International Conference on Integrated Intelligent Computing (ICIIC 2010) Published by IEEE Computer Society Press, pp. 171-176, 2010.

[50] R. Ravindra Kumar, K.G. Sulochana, and T.R. Indhu , "Online Handwriting Recognition for Malayalam Script", International conference on Information Systems for Indian languages (ICISIL 2011) Published by Springer Berlin Heidelberg, pp. 199-203, 2011.

[51] Amritha Sampath, Tripti C, Govindaru V, "Freeman Code Based Online Handwritten Character Recognition for Malayalam Using Backpropagation Neural Networks", Advanced Computing: An International Journal (ACIJ), Vol.3, pp. 51-58, 2012.

[52] Anuj Sharma, Kalpana Dahiya, " Online Handwriting Recognition of Gurumukhi and Devanagiri Characters in Mobile Phone Devices", International Conference on Recent Advances and Future Trends in Information Technology (iRAFIT2012), pp. 37-41, 2012 .

[53] U. Pal, R. Jayadevan, N. Sharma , "Handwriting Recognition in Indian Regional Scripts: A Survey of Offline Techniques', ACM Transactions on Asian Language Information Processing, vol. 1, no. 1, 2012.

IOSR Journal of VLSI and Signal Processing (IOSR-JVSP) is UGC approved Journal with Sl. No. 5081, Journal no. 49363.

Ravneet Kaur. "Online Handwritten Text Recognition for Indian Scripts." IOSR Journal of VLSI and Signal Processing (IOSR-JVSP) 7.4 (2017): 39-50. 